\title{
Los Cuentos y Novelas de Haroldo Conti
}

Haroldo Conti nació en Chacabuco, provincia de Buenos Aires, Argentina, en 1925. Pertenece al grupo de narradores argentinos que se dieron a conocer en la década 1955-1965. Esos escritores vivieron con particular intensidad y desconcierto los sucesos politicos y sociales determinados por el triunfo del régimen peronista. Manifestaron luego, casi todos, un vivo disconformismo ideológico que se tradujo en el tratamiento realista de asuntos relacionados con la situación social y política del país. Tal fue la tendencia predominante, con los matices impuestos por el temperamento personal o las influencias más marcadas. Otros, los menos, se apartaron de ella y cultivaron la fantasía o la alegoría.

La primera narración de Conti, "La causa", apareció en 1961, en un volumen que reune los cuentos y relatos premiados el año anterior en un concurso literario para América Latina organizado por la revista Life en español. Es un relato largo que describe la vida en un país latinoamericano sometido a una dictadura militar. $\mathrm{La}$ identidad del país está encubierta con el nombre ficticio de "Indiana". La época, hacia 1950. En situaciones simultáneas que cortan reiteradamente el desarrollo narrativo se presentan distintos sectores sociales y su actitud frente al régimen: campesinos, obreros, estudiantes, intelectuales, militares. Hay choques entre el ejército y los trabajadores, conspiraciones, atentados terroristas, crímenes políticos. La multiplicidad de situaciones y personajes desarticula el relato y altera el tono narrativo, que pasa de lo satírico a lo dramático y viceversa. Resulta sensible, así, la falta de unidad.

La novela Sudeste se publicó en 1962. La acción transcurre diez o quince años antes de esa fecha y tiene por escenario el Delta del Paraná. Su protagonista, "el Boga", es un peón isleño que trabaja en la zafra del mimbre. Tras la muerte de su patrón, se convierte en pescador errabundo. Se ampara en cobertizos y refugios abandonados y afronta diversas peripecias. Un extraño personaje, "el hombrecito", aparece un día en su refugio, se instala allí y lo ayuda en sus tareas. Poco después, 
al salir del riacho que recorre en su bote y al desembocar en el gran Paraná de las Palmas - que se abre, a su vez, al Río de la Plata-, el Boga encuentra en un recodo, encallado en la orilla, un batco abandonado. La embarcación, iluminada por el sol, resplandece ante los ojos del pescador como una visión deslumbrante. Este barco, revestido de connotaciones simbólicas, juega un papel decisivo en la vida del protagonista. En él encuentra una tarde, al volver de su jornada de pesca, a un hombre malherido. Es un delincuente. Sus propios compañeros lo han querido matar. Con la ayuda de el Boga, "el hombre" se repone. A poco, reanuda sus correrías de ladrón y contrabandista y arrastra consigo a los otros, entre los cuales está también el Chino o "Ia Rubia", uno de sus amigos. "El hombre" puede así vengarse de los antiguos secuaces. Luego, tras asaltar e incendiar otra embarcación, son ultimados a balazos. El Boga se arrastra hasta un bote y consigue llegar al barco abandonado. Con sus últimas fuerzas, sube a la borda. Allí muere.

Los personajes son seres primitivos, de psicología muy simple. Más que caracteres, parecen tipos; mejor aún, símbolos. Las designaciones más reiteradas - "el hombre", "el hombrecito", "él"- sugieren ausencia de individualidad, condición de seres genéricos y aun alegóricos. Pasivamente, con una pasividad fatalista, el Boga se deja arrastrar y se convierte en delincuente. Poco conocemos de su interioridad. Los asomos introspectivos se resuelven en toques líricos: "No estaba realmente enojado, como podía creerse, sino más bien preocupado. $\mathrm{Y}$ no era tan sólo por este hombrecito, que viene y se va con el río, sino por algo que parecía llegar con él, o tras él, algo oscuro e impreciso, algo que atravesaba el invierno y se perdía a lo lejos, y era como un pájato silencioso que remonta el vuelo al oscurecer". ${ }^{1}$

El título de la novela alude al viento que castiga la zona. El paisaje es un elemento importante. El río, las islas, el sol, están siempre presentes. La visión de este escenario es impresionista, en continua vibración y fluencia. El sol resplandece en el cielo y en el agua, disuelve el perfil de los árboles y las islas. Los juegos de la luz y el movimiento de las aguas son aprehendidos con un vigor $\mathrm{y}$ acierto reveladores de una honda familiaridad con el medio:

El sol rojizo del atardecer alumbró entre los árboles, llevándose las sombras hacia la otra orilla. No podían mirar hacia atrás. La luz borró cuanto tenían a sus espaldas y ahora estaban sentados contra la luz. Después el sol desapareció y sobrevino un momento

1 Sudeste (Buenos Aires, 1962), p. 87. 
de infinita quietud. Las sombras brotaron del suelo con un olor húmedo a hojas envejecidas. Vieron crecer el agua, lenta y empeñosamente, sentados en la orilla, y él había olvidado el motivo por el cual estaban ahí. Todavía quedaba un poco de luz en el medio del río. $\mathrm{E} l$ agua arrastraba algunas ramas. $\mathrm{Y}$ trajo yuyos que habían cortado más arriba y una caja de cartón. Se deslizaban en silencio, con un impulso parejo, como si estuviesen montados sobre una cinta mecánica. Ellos estaban quietos y silenciosos y adormecidos; el río, en cambio, parecía animado por una urgencia desconocida. La caja de cartón tropezó con un extremo del cabo de acero, vaciló un instante como si lo tanteara y después lo eludió girando sobre sí misma. Se estaba adormeciendo. Oyó, muy lejano, el ruido de una lancha colectiva. Más cerca, sobre su cabeza, el leve alboroto de los pájaros acomodándose en las copas de los árboles. Una gallineta comenzó a chillar en algún lugar del monte. Después el silencio fue más intenso y pareció palpitar en sus oídos. ${ }^{2}$

El relato se desarrolla en forma lineal. El ritmo es lento al principio; luego, con la aparición de nuevos personajes, se acelera y la acción cobra intensidad dramática. El punto de vista oscila ambiguamente entre la objetividad y la omnisciencia, la omnisciencia y la identificación directa con el alma del protagonista. Los límites entre autor y protagonista resultan a veces borrosos; no sabemos bien, en diversos pasajes, a cuál de los dos pertenecen algunos pensamientos. ${ }^{3}$ El tono del relato

2 Ibidem, p. 141.

${ }^{3}$ María Hortensia Lacau, en un fino análisis de Sudeste, escribe: "¿Quién narta? Difícil responderse. La posición varía como el cauce del río-protagonista. El personaje principal, el Boga, a menudo aparece no nombrado expresamente. Está como inferido, tácito, como flotando por encima de un acuerdo previo, a través de la variación pronominal ("... preguntó..." "le parecía..."). O mediante el sujeto tácito, o mediante el pronombre él. En ocasiones el narrador narra en tercera persona y desde afuera. Asume el aire de no saber qué pasa en sus criaturas literarias, de solamente suponerlo: "A veces el agua pasaba de las rodillas, pero ellos parecían insensibles a todo eso..." A veces asume formas impersonales: "...No se puede decir que el tío cambie de una manera en verano y de otra en invierno..." "Dos meses más tarde, cuando se puede suponer que había olvidado el asunto..." En ocasiones se identifica con el protagonista haciéndose vocero de sus pensamientos: "Uno duda del río y parece que es imposible llegar alguna vez..." "Uno mismo es invierno..." "...uno mismo es verano..." Estas dos últimas actitudes comportan monólogos interiores que parecen ser del Boga. Pero... ¿lo serán? ¿O será Haroldo Conti que rememora sus contactos profundos con el Delta? Por último, predomina la posición de narrador omnisciente, que todo lo sabe de sus criaturas literarias." ("Sudeste, novela de tiempo lento y paisaje existencia", Bibliograma (Buenos Aites, septiembre-octubre de 1963). 
es también ambiguo: fluctúa entre lo lírico y lo coloquial. El tono coloquial desciende a menudo a lo vulgar, como si el narrador fuera uno de los personajes. El estilo, algo descuidado, es pródigo en cierto tipo de muletillas:

Naturalmente, el dolor no era para él lo mismo que el placer pero, en el fondo, el límite entre uno y otro, y el límite entre todas las cosas, aparecía bastante borroso. La vida lo atravesaba a él como un río. El dolor y el placer se sucedían inesperadamente, uno traía al otro, cada cosa traía a la otra, de manera que si se mira bien todo era en el fondo la misma cosa, una agua oscura e incontenible corriendo en forma interminable. El aceptaba todo, en cierta forma era todo. No habría sido capaz de rebelarse contra nada, ni forzar la vida, el río, en lo más mínimo."

Expresiones semejantes se suceden a lo largo de todo el libro e inducen a creer que no revelan solamente el pensamiento del protagonista. El mundo espiritual de la novela es inseguro y misterioso. En él actúan fuerzas invisibles y todopoderosas. El Boga las intuye; por eso se deja arrastrar sin oponer resistencia. Hay, pues, una concepción mística y pesimista de la vida. $\mathrm{Y}$ sin embargo, paradójicamente, se tiene la impresión de que Sudeste muestra alguna afinidad con esos relatos de Horacio Quiroga o de Hemingway en que se exalta el esfuerzo y la lucha del hombre y en los que hay una visión del mundo afirmativo y heroica. Se trata, sin duda, de semejanzas exteriores determinadas por la similitud de ciertos motivos y procedimientos. ${ }^{5}$

Todos los veranos, conjunto de relatos, apareció en 1964. El que da título al libro está desarrollado en primera persona: el narrador evoca la figura de su padre, un personaje pintoresco, mezcla de pescador y contrabandista, que recuerda bastante al Boga. El ambiente en que viven, las actividades que realizan, el anhelo de poseer un barco y el

4 Sudeste, p. 70.

5 Refiriéndose al contenido ideológico de su obra, Conti declaró: "Yo puedo garantizar una militancia política en la acción concreta, pero no una novela revolucionaria, por más buena voluntad que ponga. Además ¿qué se entiende por una novela revolucionatia, aquí y ahora? Yo creo que se puede hacer una lectura política de Sudeste, pongamos por caso. Hay aquí una valoración del trabajo (el trabajo manual), por ejemplo. Yo no me propuse eso expresamente. No recuerdo bien lo que me propuse. Un día empecé a escribir y otro día dejé de hacerlo. La única vez que tenté algo distinto, aparte de contar una historia, fue con 'La causa', que resultó un laborioso panfleto." (De un diálogo con el periodista Isaías Peña Gutiérrez, en Vanguardia Dominical, Bucaramanga, Colombia, 21 de noviembre de 1971). 
significado que éste adquiere en la existencia de ambos, son rasgos que los aproximan. A pesar de algunos toques humorísticos, la evocación tiene un tono nostálgico y lírico que en ciertos momentos recuerda las hondas rememoraciones autobiográficas de Pavese:

Recuerdo esos días, recuerdo el aire y la luz de esos dias, porque fue la primera vez que sentí los mismos síntomas que mi padre, esa oscura ansiedad que me oprimía el pecho. Por primera vez, como mi padre, sentí la alegría y la tristeza de ser un hombre solitario, y ansié metas distantes $y$ aguardé la mañana seguro de grandes acontecimientos, y por la noche me estremecí de imprecisos deseos, percibiendo voces y ruidos remotos suspendidos como esferitas en la laxitud de las sombras, desplazándose según el viento. ${ }^{6}$

El relato carece de acción o intriga; es la suma de motivos o situaciones que van componiendo la figura del personaje evocado. Algunas de esas situaciones no son significativas; el relato hubiera ganado con una mayor concisión.

"Los novios" es la historia de una marchita pareja de festejantes, $\tan$ alejados de la vida y el amor verdaderos que apenas pueden cambiar entre sí algunas palabras sobre el tiempo. El tono es entre sentimental e irónico, de una ironía tierna y piadosa. El cuento no ha sido trabajado suficientemente. Los personajes y el escenario pueblerino están presentados de un modo esquemático y aun negligente. "Ad Astra" es una narración alegórica. El protagonista - nuevo Icaro- quiere emular a los pájaros, y lo consigue. Cuando consiente en hacer una demostración pública de su hazaña, se precipita a tierra desde lo alto de un cerro. Como en "Todos los veranos", el relato afloja en algunos pasajes por falta de concisión. "Muerte de un hermano" trae el recuerdo de cuentos como "El hijo", de Horacio Quiroga, o "La noche boca arriba", de Julio Cortázar, que se desarrollan en dos planos: el de la realidad y el del delirio o alucinación. El procedimiento obliga a un riguroso dominio de la composición, que haga visible y coherente el cambio de planos, sea al final, como en el cuento de Quiroga, sea desde el principio, como en el de Cortázar. Nos parece que ese dominio no ha sido logrado aquí totalmente. El último relato incluido en el libro es "La causa", ya considerado.

Con otra gente, de 1967, reúne tres narraciones del libro anterior

${ }^{6}$ Todos los virranos (Buenos Aires, 1964), p. 29. 
y cinco inéditas. "Como un león" tiene por protagonista a un niño de una "villa Miseria" porteña, quien muestra su vida y sus pensamientos a través de un monólogo. Juzgado con criterio realista, el monólogo tal vez no parezca del todo verosímil. El lenguaje es demasiado elegante y preciso para el personaje. Pero la intención es, más bien, lírica: quiere aprehender el alma de ese niño a través de sus pensamientos, no de su habla. Las ideas y sentimientos son del protagonista, aunque las palabras y el estilo sean del autor. También es un niño, un niño campesino, el protagonista del relato que da título al libro. El muchacho sube un día al techo de la casa a rescatar su barrilete. Encuentra un orificicio y observa desde alli la vida de abajo: todos los que viven en la chacra, hasta entonces tan familiares, se le aparecen con una imagen distinta, como si fueran extraños; el abuelo, enfermo pero voraz e impaciente como una criatura: la madre, suftida y resignada; el padre, hosco y taciturno; la mucama y el peón, alegres y sensuales.

"Perdido" es una estampa de la ciudad, casi una instantánea. Un campesino que regresa a su pueblo se despide de un sobrino en la estación. El cuadro cobra vida y es, por su estructura, un buen ejemplo de la economía y concentración de elementos que debe caracterizar al cuento. Otra situación única y bien delimitada, pero de carácter policial y con menos relieve y verosimilitud, se desarrolla en "Cinegética". En "El último" un vagabundo cuenta su historia mientras, tumbado a orillas del camino, espera algún vehículo. La evocación, en primera persona y dirigida a los lectores, tiene un tono humorístico que poco a poco va ganando en eficacia. Pese a cierta dosis de convencionalismo, es uno de los relatos más frescos del libro.

Alrededor de la jaula, la segunda novela de Conti, apareció también en 1967. El protagonista, Milo, es un niño sin familia que vive y trabaja con Silvestre, anciano que se gana la vida manejando los juegos mecánicos instalados en la costanera de Buenos Aires, frente al balneario municipal. Un hondo afecto los une. Cuando no trabajan suelen pasear juntos por la ciudad. En el Jardín Zoológico se hacen amigos de una mangosta canina; el animal los sigue con la mirada cuando dan vuelta alrededor de la jaula. Tras la muerte de Silvestre, Milo se roba la mangosta. La historia concluye poco después, cuando el muchacho es apresado por la policía. Con este asunto, la novela parece un cuento alargado. (El tema trae a la memoria algunos de esos cuentos - "Tristeza", de Chejov, por ejemplo-, en que seres solitarios y desgraciados vuelcan su ternura en un animal o lo convierten en confidente de su 
dolor.) Tanto más cuanto que no existe una detenida pintura de caracteres.

Como en Sudeste, la elección del enfoque narrativo no parece muy bien definida. En la perspectiva de un narrador omnisciente y sereno interfiere a menudo la de un narrador agresivo que utiliza un vocabulario casi soez para calificar a figuras sin relieve que aparecen fortuita y fugazmente. En tales casos la presencia del autor (no hay otro narrador que el autor) resulta del todo inadecuada: es un serio descuido de composición que altera la coherencia interna del relato. Por otra parte, Conti incurre en esas ocasiones - por vía del lenguaje, ya que no del tema-- en uno de esos superficiales excesos que a veces dañan la obra de no pocos narradores de su misma promoción.

También el estilo muestra graves descuidos: "Milo era ya un hombre, aunque mucho no se viera por afuera. Había estirado un poco de todas partes (...) En conjunto, tenía un aspecto más bien cómico, con todo que ya na se le daba por hacerse el gracioso."7 Lo más feliz del libro está, en nuestra opinión, en ciertos rasgos descriptivos. He aqui algunos: "La jirafa tenía casi tanto público como los monos. Era una jirafa joven, y a cierta distancia parecía pintada en el aire como si se tratara de un dibujo animado y no de un animal de carne y hueso. Cuando trotaba lo hacía con movimientos largos y acompasados igual que un velero o un barrilete que planea en lo alto."8 "Estuvo un largo rato despierto. Oía todos y cada uno de los ruidos de la ciudad. Era un gran rumor que crecía hacia los cielos. Y estaba lleno de vida como un fuego encendido en la noche."9

En vida es la última novela de Conti. Premiada en el concurso de la editorial española Barral, se publicó en Barcelona en $1971 \mathrm{y}$ tuvo gran difusión en todos los países de habla hispana. La acción se desarrolla en Buenos Aires y sus alrededores, cuatro o cinco años antes de aquella fecha, aunque no hay referencias a la situación política o social del momento. El título, abstracto, con cierta sugerencia discursiva, parece anunciar la índole moral o filosófica del tema. El asunto es sencillo. Trás una noche de juerga con sus amigos, Oreste conoce a Margatita. La mujer lo lleva a su casa, cetca del tío, junto a un terraplén que se estremece con el paso de los trenes. Oreste prosigue después su vida habitual. Es redactor en una oscura publicación dedicada a cuestiones agrarias. Su vida familiar no es menos opaca y rutinaria.

7 Alrededor de la jaula (Buenos Aires, 1967), p. 56.

8 Ibidem, p. 108.

9 Ibídem, p. 114. 
Como para huir de tanta monotonía, vagabundea sin rumbo por la ciudad, de día y de noche. Pero la ciudad es también gris y opresiva. Otro recurso es la imaginación y el ensueño: la huida hacia la infancia, el recuerdo del padre y el tío, seres vagabundos y casi fantasmales. Por último, los fines de semana están las juergas con amigos, excursiones nocturnas a bares y clubes de la zona ribereña. En una de ellas había conocido a Margarita. Una semana después la vuelve a encontrar. La relación se hace ahora honda y decisiva; Oreste abandona su casa y su familia. La escena final, cuando se oculta de su hijo que ha venido a buscarlo (ésta y la del baile, en el segundo encuentro con Margarita, son las más intensas del libro), subraya el significado de aquella actitud: "Tal vez un día, cuando a su hora él también recuperara los fantasmas y las sombras, terminase por reconocer este paisaje y al hombre que acaso por primera vez había escogido algo en la vida."10

Oreste, presente a lo largo de toda la novela, tal vez no sea un personaje muy original; la literatura de posguerra ha producido muchas figuras así, frustradas y abúlicas. Pero es un personaje que convence: se lo ve y se lo siente vivir. También cobran relieve Paco, el amigo, y los compañeros de trabajo, Requena y Monteverde, aunque sean, en el fondo, variaciones del protagonista: lo confirman y vigorizan al insertarlo en un mundo en el cual no es, de ningún modo, una excepción, y acentúan el clima de uniformidad y monotonía. La mujer y la hija de Oreste son figuras borrosas; Marcelo, el hijo, aparece con trazos y en situaciones más precisos. Margarita es un personaje casi irreal: no es un ser individual sino un símbolo.

La novela se desarrolla linealmente. La acción se va trenzando con una prolija descripción de la ciudad, como si el protagonista se buscara a sí mismo en ella, y con rápidas retrospecciones que lo trasladan a la infancia y en las cuales palpitan sus temores de niño y quizá también las claves de su fracaso de hombre. La narración está en tercera persona, pero la perspectiva traduce una coincidencia de narrador y protagonista. El relato y la descripción reflejan, así, indirectamente, la interioridad de Oreste. A menudo el narrador se aparta del protagonista y lo ve desde cierta distancia, como a un petsonaje más. Así se explica la alternancia de dos tonos antagónicos: el coloquial, sembrado de vulgarismos y palabras gruesas, y el poético, manifiesto en el lenguaje sugeridor y en el uso de metáforas. En la cuerda floja de esos cambios de perspectiva, no siempre el relato mantiene el equilibrio. Surgen entonces imprecisiones como en Sudeste y desajustes como los

10 En vida (Barcelona, 1971), p. 213. 
que señalamos en Alrededor de la jaula, ahora más visibles porque se utiliza un vocabulario más rudo. Salvo esas violencias de expresión ${ }_{5 x}$ que sólo pueden ser necesarias o verosímiles en los personajes, el autor no interviene en la novela ni obstruye el desenvolvimiento del relato. con sus ideas o comentarios. No hay otra tesis que la que surge natural. mente de los sucesos y personajes: el imperativo, tan caro a la filosofía existencialista, de vivir con autenticidad y resolver libremente nuestro destino.

La materia narrativa parece intrascendente: hombres en la madurez que cumplen tareas oscuras y se distraen en juergas y aventuras de muchachos, ambientes estrechos que huelen a encierro o a cocina, una ciudad gris y opresiva. Es la materia adecuada para el propósito perseguido: mostrar una existencia desprovista de incentivos. No faltan: algunos detalles eróticos de los cuales se hubiera podido prescindir; resultan, por ello, recursos poco plausibles. El estilo desaliñado y áspero, pero eficaz, remeda esa fealdad general que la novela pretende registrar, y traduce el disgusto y amargura de los personajes. El lado poético. de ese estilo, sus imágenes y metáforas, parecerían señalar la otra realidad: la simbolizada por Margarita, su casa de madera que se eleva sobre una plataforma - como en las islas-, el terraplén y los trenes. que tompen la noche rumbo a lo desconocido.

Entre los narradores argentinos de su promoción -David Viñas, Beatriz Guido, Marta Lynch, Sara Gallardo, Humberto Constantini, Abelardo Castillo, Germán Rozenmacher, etc.-, cuyo rasgo distintivo más ostensible es un realismo inclinado a la crítica social y política, a veces alterado por un acento de cólera o de angustia, la obra de Conti se distingue por un lirismo tenue que atempera la realidad. Por otra parte, más que los temas relacionados con la vida política o social le interesan los conflictos de la conciencia individual. De allí el ritmo lento y reflexivo que se advierte en sus libros, sobre todo en los dos más significativos. El primero de ellos, Sudeste, introdujo una nota de frescura y sencillez casi única en la novelística argentina actual. Revelaba, además, varias virtudes que, en síntesis, configuran una actitud de ejemplar honradez artística: profundo conocimiento del medio y de los personajes utilizados, setio propósito de realizar un trabajo digno y despojado de recursos fáciles, hábil asimilación de lecciones muy válidas dejadas por escritores afines. Los dos libros de cuentos y la segunda novela no fueron, en nuestra opinión, tan afortunados. Aquéllos descubren que, en general, la visión y el tratamiento de la realidad son, en Conti, los de un novelista antes que los de un cuentista. La novela se 
resiente por falta de materia apropiada. En su último libro, En vida, resurge el narrador vigoroso y denso, capaz de dar otra vez la medida de su fuerte aliento creador. Si en su próxima novela puede unir a esa fuerza un mayor rigor en la composición y conserva la sobriedad y el cuidado de los detalles, ella será, sin duda, su obra más plena y cabal.

FERNANDO ROSEMBERG

Universidad de Buenos Aires, Argentina 